\title{
Production of Renewable Insulation Material - New Business Model of Bioeconomy for Clean Energy Transition
}

\author{
Ilze LUKSTA ${ }^{1 *}$, Girts BOHVALOVS ${ }^{2}$, Gatis BAZBAUERS ${ }^{3}$, Kriss SPALVINS $^{4}$, \\ Andra BLUMBERGA ${ }^{5}$, Dagnija BLUMBERGA ${ }^{6}$ \\ ${ }^{1-6}$ Institute of Energy Systems and Environment, Riga Technical University, Azenes iela 12-K1, Riga, \\ LV-1048, Latvia
}

\begin{abstract}
Mycelium composites is a new class of renewable materials which can be used for heat insulation of buildings. Use of the composites would help to reduce both operational energy consumption and embodied energy of building insulation materials. In addition, use of the renewable composites could also reduce embodied greenhouse gas (GHG) emissions of the insulation materials. Local production and use of the composites could stimulate residential building insulation process via additional socio-economic benefits, such as positive impact on local economy, created workplaces and reduced import. The research question of this study is to determine a difference between embodied energy and GHG emissions of the mycelium insulation material and synthetic insulation alternatives. System dynamics model is used as the method for assessment of the dynamics of the total embodied energy and GHG emissions if equal amounts of the insulation materials is produced. Time horizon for the modeling is 2021-2050. Data used in the model were taken from scientific publications and laboratory experiments with growth process and properties of the mycelium composites. The model includes several feedback effects, e.g., effect of research and development on efficiency and productivity of the mycelium production process. The results show that embodied energy of the mycelium insulation material is higher than for the synthetic alternatives but the embodied GHG emissions are considerably lower than for the alternatives. The embodied GHG emissions are even lower if the absorption of $\mathrm{CO}_{2}$ of renewable materials used for the production of the mycelium composites is included.
\end{abstract}

Keywords - Bioeconomy; energy efficiency; insulation of buildings; mycelium insulation material; sustainability; system dynamics modeling

\section{INTRODUCTION}

The construction industry has come under considerable pressure over the last decade as the supply of traditional building materials such as cement, brick, timber, cladding and partition materials has struggled to cope with increasing demand. Production of these conventional building materials consumes energy, limited natural resources and pollutes air, land and water. Up to $36 \%$ of the lifetime energy consumption of a typical dwelling can be attributed to harvesting or extraction of primary materials as well as other production processes, transport and construction of a building. Low-energy buildings, although using less energy, have even larger environmental impact in the construction phase (up to $46 \%$ of residential

* Corresponding author.

E-mail address: ilze.luksta@rtu.lv

(C2021 Ilze Luksta, Girts Bohvalovs, Gatis Bazbauers, Kriss Spalvins, Andra Blumberga, Dagnija Blumberga.

This is an open access article licensed under the Creative Commons Attribution License (http://creativecommons.org/

licenses/by/4.0). 
energy demand can be attributed to the building construction) due to increased heat insulation, higher density materials and additional technologies used [1].

The material that provides structural performance with minimal environmental impact is mycelium-based biocomposites [2]. Mycelium composites are a new type of novel, economical, and environmentally sustainable materials that have attracted increasing academic and commercial interests over the past decade. Mycelium is the vegetative growth of filamentous fungi that bonds organic matter through a network of hyphal microfilaments in a natural biological process that can be exploited to produce composite materials [1].

Mycelium composites have customizable material properties due to their composition and manufacturing process, and they can replace foam, wood and plastics for such applications as insulation, panels, floors and furniture. The materialhas low thermal conductivity, high acoustic absorption and fire safety properties that surpass traditional building materials such as synthetic foam. However, there are limitations, such as mechanical properties, water absorption and other properties, which must be assessed when the composite is used in building materials. Nevertheless, the useful material properties, in addition to low cost, ease of manufacture and environmental sustainability suggest that they will play an important role in the future of environmentally friendly construction [1]. Many natural materials have fiber architecture. Examples are many, including silk spider webs, bone, plant stems such as bamboo, connective tissue. The design of these natural materials has inspired researchers to imitate such synthetic architectural materials, although this has proven to be a difficult task in many cases. A new approach to this problem is designed engineering components, obtained by direct growing of a natural material in the desired form. Such components inherit microstructure and properties of the base materials [3]. Compared to synthetic composites, a composite made from mycelium and other natural materials yields a low-density material with high strength and an opportunity for lowered embodied energy. Furthermore, the inclusion of a natural cellulosic textile for reinforcement allows for reuse of an otherwise-waste material and expands the composite's end of life options [4].

Mycelium has the unique ability to form composite materials quickly and easily [4]. From the perspective of a raw fiber resource, fungi can beat lignocellulosic textiles in terms of energy and physical properties [5]. Due to its unique structure and composition, it may be possible to produce large quantities of mycelium-based materials [6]. Mycelium 'acts like a natural, self-assembling glue that digests and binds securely to natural reinforcement materials and agricultural byproducts with essentially no added energy'. Growing mycelium around other natural materials is a sustainable and efficient way to generate various products, as outlined below [4]. In the production of mycelium, it is necessary to completely stop the growth of the fungus before the substrate (such as straw or sawdust) is completely degraded. In this case, the organic fibers or particles of the hypha compound together, thus colonizing the substrates. Fungal growth can be stopped by drying and / or heating the colonized substrate. Heating destroys the fungus, but drying keeps the fungus in the 'winter' state [7].

Some recent studies have shown the competitiveness of foam-like mycelium-based composites compared to conventional materials such as expanded polystyrene (EPS) or other foams, or other bio-based composites such as hemp concrete. In general, mycelium-based materials have proven their potential to replace the use of less environmentally friendly materials, such as bioplastics or wood composites [8]. The composite is an environmentally responsible alternative to expanded polystyrene and other plastics. The material competes directly with petrochemical foams in terms of performance, cost and with low embodiedenergy [9]. The whole production process is considered to be an environmentally friendly waste stream due to valorisation, thus preventing the destruction of ecosystems and obtaining resources [10]. Mycelium materials consist entirely of renewable materials and require very 
little energy to process. Therefore, they are definitely a part of the circular economy model [11]. Due to its unique structure and composition, we anticipate the production of large quantities of mycelium-based materials. To date, mycelium has been used mainly by a US company using raw biomass glued to mycelium, resulting in foaming structures, but there is still much room for improvement and further development of mycelium-based materials [12].

The value chain of forest bio-products can be divided into several groups of activities. Production, collection, processing, storage, transport, marketing and sales are key activities in the forest product value chain, using value-added bio-based products that reach their target customers [13].

Different applications of building materials can have different areas of problems. The main concern for internal insulation materials is a transfer of moisture between the interfaces of insulation and structural materials, as the largest temperature gradient occurs at the interfaces. Condensed liquid can cause swelling and shrinkage of insulation materials or even significant reduction of insulating properties. [14] Only a few research centers and companies around the world have the knowledge and capacity to produce mycelium-related materials for the building and construction industry. Studies on the use of mycelial composites as structural elements date back to 2009, when Ganoderma lucidum and sawdust were used to create the tea house [13].

Fig. 1 shows the product development steps from materials to the energy efficient building. A new material with good technical properties is not yet ready for the market, but suitable products need to be developed. If the products do not fit into existing building systems, new systems are required for proper integration with the entire building. This requires both technical development and improved know-how in the production process, design, installation, analysis of overall performance, etc. However, radical leaps in innovation can significantly accelerate the emergence of new solutions on the market [14].

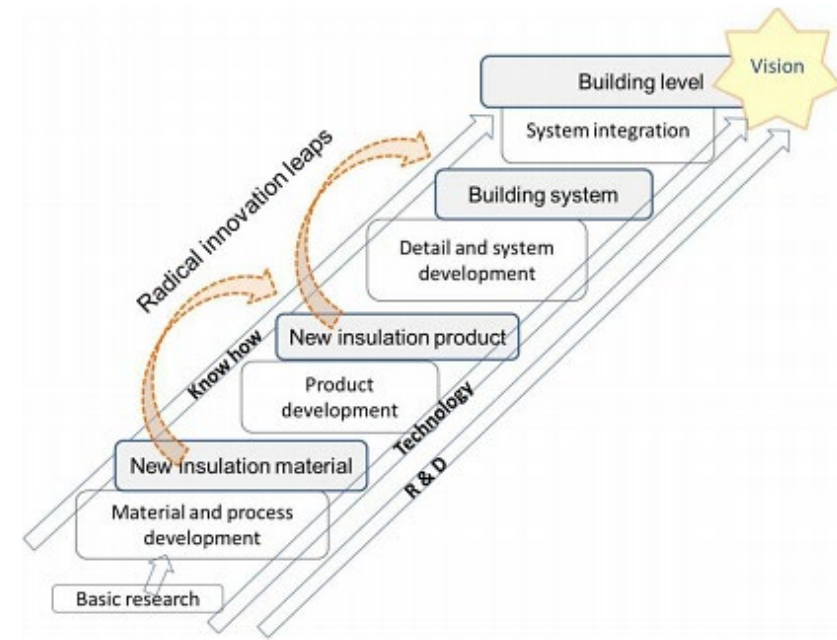

Fig. 1. Product development stages from materials to the level of energy efficient building [14].

As shown in Table 1, plant-based insulation materials (i.e. hemp, flax, rice husk, wood fibers) have competitive thermal conductivity and possibly lower costs compared to inorganic and synthetic insulation materials. From an environmental point of view, plant-based materials have significantly lower embodied energy and carbon than the fosil-based materials [15]. In addition, when designing building envelopes, thermal insulation materials 
with a higher specific heat output $\left(\mathrm{kJ} / \mathrm{m}^{3} \mathrm{~K}\right)$, such as plant-based insulation materials, can store the maximum solar radiation that absorbs the building facades and reduce the maximum cooling loads by delaying the maximum indoor temperature. caused by solar radiation during the summer [16].

TABle 1. Properties of CONVENTIONAL InSUlation MATERials [15]

\begin{tabular}{|c|c|c|c|c|c|c|c|}
\hline Material & Density & $\begin{array}{l}\text { Thermal } \\
\text { conductivity }\end{array}$ & $\begin{array}{l}\text { Specific } \\
\text { heat } \\
\text { capacity }\end{array}$ & $\begin{array}{l}\text { Water } \\
\text { vapor } \\
\text { diffusion } \\
\text { resistance } \\
\text { factor }\end{array}$ & Cost & $\begin{array}{l}\text { Embodied } \\
\text { energy }\end{array}$ & $\begin{array}{l}\text { Embodied } \\
\text { carbon }\end{array}$ \\
\hline Unit & $\mathrm{kg} / \mathrm{m}^{3}$ & $\mathrm{~W} \cdot \mathrm{m}^{-1} \mathrm{~K}^{-1}$ & $\mathrm{~J} / \mathrm{g}{ }^{\circ} \mathrm{C}$ & - & $\mathrm{USD} / \mathrm{m}^{3}$ & $\mathrm{MJ} / \mathrm{kg}$ & $\mathrm{kgCO}_{2 . \mathrm{eq}} / \mathrm{kg}$ \\
\hline \multicolumn{8}{|l|}{ Plant-based } \\
\hline Hemp & $25-100$ & $0.039-0.123$ & $1.7-1.8$ & $1-10$ & $15-19.4$ & 18.71 & 0.14 \\
\hline Flax & $20-100$ & $0.033-0.09$ & 1.6 & $1-5.28$ & 15.18 & 39.5 & 20 \\
\hline Rice husk & $130-170$ & $0.048-0.08$ & $1.2-2.7$ & 2 & 5 & 1.36 & 0.6 \\
\hline Wood fiber & $50-270$ & $0.038-0.05$ & $1.9-2.1$ & $1-5$ & $26.6-37.8$ & 20.3 & 0.124 \\
\hline \multicolumn{8}{|c|}{ Inorganic (fibrous \& foam) } \\
\hline Glass wool & $10-100$ & $0.03-0.05$ & $0.8-1$ & $1-1.3$ & $9.3-14.7$ & $14-30.8$ & 1.24 \\
\hline Rock wool & $40-200$ & $0.033-0.04$ & $0.8-1$ & $1-1.3$ & $12-20$ & 16.8 & 1.05 \\
\hline \multicolumn{8}{|c|}{ Synthetic foams } \\
\hline EPS & $18-50$ & $0.029-0.041$ & 1.25 & $20-100$ & $8.6-17$ & $80.8-127$ & $6.3-7.3$ \\
\hline XPS & $32-40$ & $0.032-0.037$ & $1.45-1.7$ & $80-170$ & $18-23$ & $72.8-105$ & 7.55 \\
\hline Polyurethane & $30-160$ & $0.022-0.035$ & $1.3-1.45$ & $50-100$ & 24.91 & $74-140.4$ & 5.9 \\
\hline $\begin{array}{l}\text { Phenolic } \\
\text { foam }\end{array}$ & $40-160$ & $0.018-0.024$ & $1.3-1.4$ & 35 & 23 & $13-159$ & $4.15-7.21$ \\
\hline
\end{tabular}

The Global Sustainable Development Strategy implies reduction of non-renewable materials by replacing them with bio-based materials. In addition to biological materials, such as bioplastics, bacteria, algae or fungi materials are increasingly being used as innovative biobased alternatives [6].

Analysis of scientific articles shows that so far only bog-type mushroom materials have been analyzed and used; therefore, within this study the use of mold mushrooms in production of thermal insulation materials was studied. Although molds were considered harmful to human health, not all of them have an adverse effect on the human body, as the experimental mushrooms are used in the production of fertilizer, as well as the growth of mushroom hyphae is stopped and neutralized during the drying process. Drying of the material is necessary because by removing moisture from the material, the spores of the fungus are no longer able to absorb nutrients and multiply, and are therefore neutralized by returning to a previous safe state. Mushroom spores never really 'die' because they can always start to multiply again later when new moisture becomes available. Therefore, the mycelium material must be provided with a coating that prevents the formation of moisture in the material, as well as preventing the mold from 'reviving' and continuing to grow. Mold can grow in the temperature of $\sim 25-30{ }^{\circ} \mathrm{C}$, as well as provide $90-100 \%$ relative humidity in the room. Given these factors, it is possible to avoid the 'revival' and the growth of the fungus.

The goal of this study is to compare mold mushroom embodied emission and energy between synthetic materials. 


\section{METHODOLOGY}

The system dynamics approach, which is a mathematical method used to study and manage complex systems that change over time based on causes and feedback loops, was used in the study. This approach was developed in the Massachusetts Institute of Technology by Professor Jay Wright Forrester in 1956 [17]. Stella Architect has been used as a software tool for building stock and flow structure and simulation of system's behavior. The model was used to compare differences between the production of mycelium insulation material and four other synthetic insulation materials: expanded polystyrene (EPS), extruded polystyrene (XPS), polyurethane, and phenolic foam. Average values of synthetic insulation materials were taken from the thesis [15]. The comparison is made based on volumes of the produced insulation materials that provide equal heat insulation properties (thus, considering differences in themal conductivity). The focus of comparison was on the difference in embodied GHG emissions and embodied energy of materials in the cradle-to-gate life-cycle stage and the results are expressed per cubic meter of insulation material as well as in form of cumulative values of embodied GHG emissions and embodied energy. The time period of calculations is set from 2021 to 2050. The time span of 30 years was chosen for simulation because most of EU climate policies are concerned with the time period of up to 2050, when climate neutrality has to be reached. Since the simulation includes not only building up a capacity for mycelium insulation material production but also effects of research and development $(\mathrm{R} \& \mathrm{D})$ on production efficiency of the material, the time period has to be sufficiently long to reflect these effects.

\subsection{Structure of the Model}

A causal loop diagram (CLD) was used to describe the structure of the modeled system, and it was created before model construction (Fig. 2). CLD depicts the mechanics of a system without calculations [18]. CLD illustrates the main feedback structure of the system and captures the causes of the dynamics. Three reinforcing and four balancing loops represent the studied system (Fig. 2). Reinforcing loops exhibit exponential growth behavior. Reinforcing loop R1 shows how the production of mycelium insulation material increases the amount of reduced (avoided) GHG emissions since the material substitutes synthetic one with higher embodied GHG emissions. The more emissions are reduced the more carbon allowances can be sold providing revenues. Part of the revenues can be invested in the increase of allocated land for production resulting in increased capacity of production technologies which allow increased use of renewable insulation materials even more. The reinforcing loop R2 describes the feedback, where part of the revenues from sales of carbon allowances is invested in research and development to increase the energy efficiency of production. An increase in energy efficiency increases the amount of reduced emissions even more. It takes time for the research and development process to reduce energy consumption, and this is modeled by assuming that the investment in the research and development reduces the time it takes to move through stages of the research and development process. The production capacity is limited by the availability of the raw material, and the limit to the energy efficiency is a certain maximum value. Reinforcing loop R3 conveys how investment in research and development increases the amount of insulation material produced per area, i.e. production yield. As production yield increases, so does the use of renewable insulation materials increasing the amount of emissions reduced compared to the synthetic insulation materials, even more, thus increasing revenues from sales of carbon allowances. That, in turn, increases potential investment in research and development even more. 
Balancing, also known as negative feedback loops, lead to the goal-seeking behavior of a system. The first balancing loop B1 shows how the use of raw material availability interacts with raw material consumption for the production of the mycelium insulation material, i.e. use of renewable insulation materials. The raw material consumption results in the insulation material production and the more insulation material is produced, the less raw materials are left from which to produce. The second balancing loop B2 shows how energy efficiency interacts with the remaining potential for energy efficiency increase. In this study, energy efficiency increase is made by investment in research and development. Revenues from that investment come from sales of carbon allowances. The more energy efficiency is increased, the less it can be increased next turnaround. A similar effect of depletion of potential for production yield improvement can be portrayed by the balancing loop B3 and also for land allocated for production in loop B4.

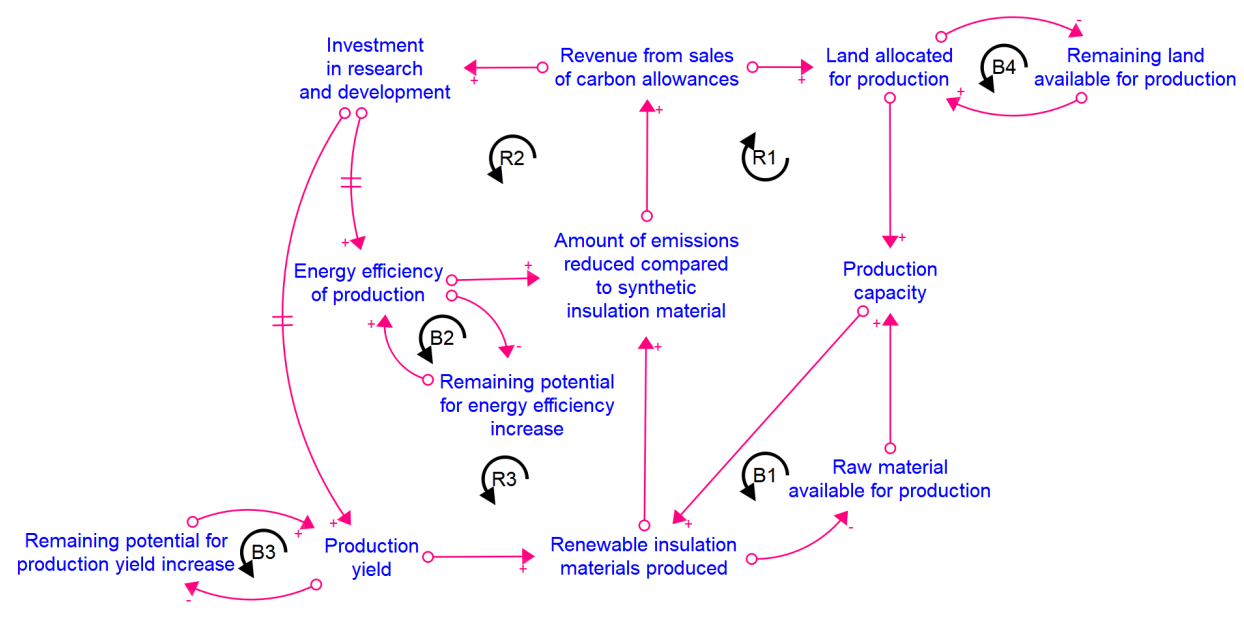

Fig. 2. Causal loop diagram portraying structure of the system dynamics model for mycelium insulation material production.

\subsection{Data Collection}

For the calculation of embodied emissions of mycelium insulation material, emission factors and emission absorption of materials, as well as data on the consumption of electricity and heat are required. The same applies to embodied energy calculation where instead of emission factors, embodied energy of materials is used. The materials required to produce 1 $\mathrm{m}^{3}$ of mycelium insulation material were taken from laboratory experiments done at Riga Technical University. The mycelium embodied emission and energy data is not included, because a fraction of the material inputs are used for bioreactor feed to grow mold mushrooms. Materials, electricity, and heat required for production, emission factors, emission absorption, and embodied energy input data can be seen in Table 2 . 
TABLE 2. EMISSION FACTORS AND EMBODIED ENERGY OF PRODUCTION INPUTS PER $1 \mathrm{M}^{3}$ OF MYCELIUM INSULATION MATERIAL

\begin{tabular}{lllll}
\hline Input & $\begin{array}{l}\text { Input in } \\
\text { production, unit } / \mathrm{m}^{3}\end{array}$ & $\begin{array}{l}\text { Emission factor, } \\
\mathrm{kgCO}_{2 \mathrm{eq}} / \mathrm{unit}\end{array}$ & $\begin{array}{l}\text { Emission } \\
\text { absorption, } \\
\mathrm{kgCO}_{2 \mathrm{eq}} / \mathrm{unit}\end{array}$ & $\begin{array}{l}\text { Embodied energy, } \\
\mathrm{MJ} / \mathrm{unit}\end{array}$ \\
\hline Mycelium, kg & 0.117 & - & $0.0025[19]$ & - \\
Distilled water, kg & 259.3 & $0.0008[20]$ & 0 & $23[21]$ \\
Molasses, kg & 7.5 & $0.074[22]$ & $0.1[23]$ & $1[23]$ \\
Starch, kg & 6.4 & $2.4[24]$ & $0.174^{*}[25]$ & $0,0014[25]$ \\
Whey powder, $\mathrm{kg}$ & 7.5 & $0.082[26]$ & $0.98[23]$ & $20[23]$ \\
Carbamide, $\mathrm{kg}$ & 0.97 & $1.85[27]$ & $0.73[28]$ & $49[28]$ \\
Xanthan, kg & 2.3 & $0.00497[29]$ & $0.048[30]$ & $7.6[31]$ \\
Soda, $\mathrm{kg}$ & 13.6 & $0.00059[20]$ & $0.524[32]$ & $26.9[32]$ \\
Wood Chips, $\mathrm{kg}$ & 189.3 & $0.000187[33]$ & $1.835^{*}$ & $17[34]$ \\
Straw, $\mathrm{kg}$ & 63.1 & $0.1036[35]$ & $1.468^{*}[36]$ & $2.125[37]$ \\
Electricity, $\mathrm{kWh}$ & 988 & $0.1019[38]$ & 0 & 3.6 \\
Heat, $\mathrm{kWh}$ & 754 & $0.0942[38]$ & 0 & 3.6 \\
\hline
\end{tabular}

*Value was calculated for this study

\subsection{Modelling}

Some elements of the model were taken from the already existing model made for bioeconomy sector at Riga Technical University [39] then modified and further developed for this study. The model was adjusted to simulate a factory-like environment for material comparison. Multiple changes were made regarding raw material availability, available area, production, research and development, emissions, as well as new sectors were added named 'energy' and 'functional cubic meters'.

\subsubsection{Available Area and Raw Material Availability}

To determine the area used for material production, an assumption is made that the total land available for production is $10000 \mathrm{~m}^{2}$. Land initially used is $1000 \mathrm{~m}^{2}$ and the remaining $9000 \mathrm{~m}^{2}$ are available to allocate for production based on the initial time of land allocation and income from carbon trade. An increase in income from carbon trade decreases the time of land allocation, therefore increasing the land allocation rate and the area allocated for production.

Mycelium insulation production requires 9 raw input materials. The raw materials are restocked annually based on production area and production yield of input materials.

\subsubsection{Production Process}

Raw material inputs are accumulated in a single stock and summed up to determine the annual potential production rate. The stock acts as a limit to production as it is not possible to produce more material than the accumulated raw material. Production is not only dependent on the accumulated material and potential production but also production capacity in operation. Production capacity in operation is the maximum possible production amount, as 
it is not possible to produce more insulation material than technical equipment is capable to produce.

\subsubsection{Research and Development}

It is assumed that the electricity requirement of production can be reduced by $30 \%$ and heat requirement by $45 \%$. The initial time to research energy efficiency improvement is set for 5 years and the initial time to develop solutions from labs to implementation phase is 3 years. Initial production yield is set to $90\left(\mathrm{~m}^{3} / \mathrm{m}^{2}\right) /$ year and it can be increased up to 120 $\left(\mathrm{m}^{3} / \mathrm{m}^{2}\right) /$ year. The initial time to research yield is set to 50 years and the time to implement solutions - to 25 years. There is also the time needed for educating with the new solutions and it is set to 10 years. The time to educate is not influenced by research and development. The research and development time can be influenced by the amount of financial support towards the research and development. Funding for the research and development is obtained from selling avoided $\mathrm{CO}_{2}$ emissions. That investment into research and development decreases 'time to research' and 'time to development' by up to two times.

\subsubsection{Emissions}

Each material used in production causes a certain amount of emissions per ton used. Knowing the amount of material used in the production of the insulation material the emissions from the materials (embodied emissions) were calculated by multiplying the amount of the raw material used by its emission factor. Similarly, the amount of carbon dioxide $\left(\mathrm{CO}_{2}\right)$ absorbed is calculated using the absorption factor instead of the emission factor. Annual emissions from each material were summed up to determine the total amount of emissions from material use. For electricity and heat emissions, the annual consumption rate was taken and multiplied by its emission factor for each consumption then summed up to find out the annual emission amount from energy consumption. To find out mycelium insulation material emission factor both annual material use emissions and energy consumption emissions were summed together and divided by the total amount of produced mycelium insulation material.

Emission factors of other synthetic materials were used to calculate the difference in emissions in material production per cubic meter of insulation material. The difference was used to compare the amount of avoided emission by the production of mycelium insulation material instead of other synthetic material. A comparison was also made in cumulative emissions for each insulation material.

\subsubsection{Energy}

Approach calculation of embodied energy was very similar to the calculation of the embodied emissions. Input material embodied energy was multiplied by the amount of input material, and then electricity and heat consumption are added, and summed energy was divided by the amount of material produced. The difference between the mycelium insulation material and other materials was used to calculate the avoided energy consumption. Cumulative energy consumption during the production process of each material was also determined.

\subsubsection{Functional Cubic Meters}

Since the considered insulation materials have different thermal conductivity, a correction has to be made to make comparison based on the amount of materials providing the same heat 
insulation properties. Therefore, we introduce 'functional cubic meters' $\left(\mathrm{fm}^{3}\right)$ which is an amount of insulation material required to have the same heat flux value as a material in comparison. The correction is done by calculating ratios of thermal conductivities of the considered insulation matarials to the thermal conductivity of the mycelium insulation material (see Table 3.). To calculate functional embodied emissions and functional embodied energy, the ratios were multiplied by embodied emissions and embodied energy of the considered insulation materials. To calculate thermal conductivity of the mycelium material, thermal conductivity values of the raw material components were taken from Table 1. and calculated to an average value.

TABLE 3. INSUlATION MATERIAL THERMAL CONDUCTIVITY VALUES AND THERMAL CONDUCTIVITY TO MYCELIUM THERMAL CONDUCTIVITY RATIO

\begin{tabular}{lll}
\hline Material & $\begin{array}{l}\text { Thermal conductivity, } \\
\mathrm{W} /(\mathrm{mK})\end{array}$ & $\begin{array}{l}\text { Ratio to mycelium thermal conductivity, } \\
\text { unitless }\end{array}$ \\
\hline Mycelium insulation & 0.04 & 1 \\
EPS & 0.035 & 0.875 \\
XPS & 0.0345 & 0.863 \\
Polyurethane & 0.0285 & 0.713 \\
Phenolic foam & 0.021 & 0.525 \\
\hline
\end{tabular}

\section{RESUlts AND Discussion}

\subsection{Embodied Emissions and Embodied Energy}

The initial embodied emission value of the mycelium heat insulation material is $213 \mathrm{kgCO}{ }_{2} \mathrm{eq} / \mathrm{m}^{3}$, and as research and development decrease the amount of electricity and heat required to produce $1 \mathrm{~m}^{3}$ of material the embodied emissions are reduced to $159 \mathrm{kgCO} 2 \mathrm{eq} / \mathrm{m}^{3}$. Material use initially contributes to $19 \%$ of production emissions or $40 \mathrm{kgCO}_{2} \mathrm{eq} / \mathrm{m}^{3}$, heat use $33 \%$ or $71 \mathrm{kgCO} 2 \mathrm{eq} / \mathrm{m}^{3}$ and electricity $48 \%$ or $101 \mathrm{kgCO} \mathrm{eq}_{2} / \mathrm{m}^{3}$. In 2050, emissions from the material use stay the same only having a higher share of $27 \%$, emissions from heat have lowered to $26 \%$ or $39 \mathrm{kgCO}_{2} \mathrm{eq} / \mathrm{m}^{3}$, and emissions from electricity $47 \%$ or $70 \mathrm{kgCO}_{2} \mathrm{eq} / \mathrm{m}^{3}$. The mycelium insulation material has lower embodied emission values than other examined materials (see Table 4). When counting in $\mathrm{CO}_{2}$ absorption, mycelium insulation material embodied emission value initially is $-244 \mathrm{kgCO}_{2} \mathrm{eq} / \mathrm{m}^{3}$ and with the decrease of energy requirement, embodied emissions are reduced to $-298 \mathrm{kgCO}_{2} \mathrm{eq} / \mathrm{m}^{3}$. When the values of embodied emissions are compared on the basis of 'functional $\mathrm{m}^{3}$ ' then differences between the mycelium and synthetic materials are smaller (see Table 4) due to lower thermal conductivity of the synthetic materials.

Decrease in electricity and heat requirement also reduces embodied energy of the mycelium insulation. The initial embodied energy of mycelium insulation material is $16176 \mathrm{MJ} / \mathrm{m}^{3}$ and in 2050. with the decrease of heat and electricity requirements, the value of embodied energy is reduced to $14071 \mathrm{MJ} / \mathrm{m}^{3}$. Most of the embodied energy comes from material use. Initially, materials result in $61 \%$ of all embodied emissions, but as heat and electricity requirement decreases material embodied energy share goes up to $71 \%$. All synthetic materials have lower per $1 \mathrm{~m}^{3}$ of insulation material embodied energy values than the mycelium insulation. The compared material embodied emission and embodied energy values stay constant during the production period. 
TABLE 4. THE INITIAL EMBODIED EMISSION AND ENERGY VALUES PER $1 \mathrm{M}^{3}$ AND FUNCTIONAL $1 \mathrm{M}^{3}$ OF MYCELIUM INSULATION AND SYNTHETIC INSULATION MATERIALS

\begin{tabular}{|c|c|c|c|c|}
\hline Material & $\begin{array}{l}\text { Embodied } \\
\text { emissions, } \\
\mathrm{kgCO}_{2} \mathrm{eq} / \mathrm{m}^{3}\end{array}$ & $\begin{array}{l}\text { Embodied emissions, } \\
\mathrm{kgCO}_{2} \mathrm{eq} / \mathrm{fm}^{3}\end{array}$ & $\begin{array}{l}\text { Embodied } \\
\text { energy, } \mathrm{MJ} / \mathrm{m}^{3}\end{array}$ & $\begin{array}{l}\text { Embodied } \\
\text { energy, } \mathrm{MJ} / \mathrm{fm}^{3}\end{array}$ \\
\hline Mycelium insulation & 213 & 213 & \multirow[t]{2}{*}{16176} & \multirow[t]{2}{*}{16176} \\
\hline $\begin{array}{l}\text { Mycelium insulation } \\
\text { (including } \mathrm{CO}_{2} \text { absorption) }\end{array}$ & -244 & -244 & & \\
\hline EPS & 231.2 & 202 & 3532 & 3091 \\
\hline XPS & 271.8 & 234 & 3200 & 2760 \\
\hline Polyurethane & 560.5 & 399 & 10184 & 7256 \\
\hline Phenolic foam & 1136 & 596 & 8600 & 4515 \\
\hline
\end{tabular}

\subsection{Accumulated GHG Emissions}

The mycelium insulation material has the lowest emissions per cubic meter of material (Fig. 3), therefore the cumulative emission value during the production process is the lowest. Mycelium insulation cumulatively emits $3.58 \mathrm{MtCO}_{2}$ eq. If $\mathrm{CO}_{2}$ absorption is included, then it is estimated that the mycelium insulation material absorbs $6.26 \mathrm{MtCO}_{2}$ eq. Emissions of the synthetic materials are: EPS 4.3 $\mathrm{MtCO}_{2} \mathrm{eq}$, XPS $4.98 \mathrm{MtCO}_{2} \mathrm{eq}$, polyurethane $8.48 \mathrm{MtCO}_{2} \mathrm{eq}$ and phenolic foam 12.7 $\mathrm{MtCO}_{2}$ eq. Correction of amounts of the materials due to differences in thermal conductivity was done as described above. The same applies to cumulative energy consumption.

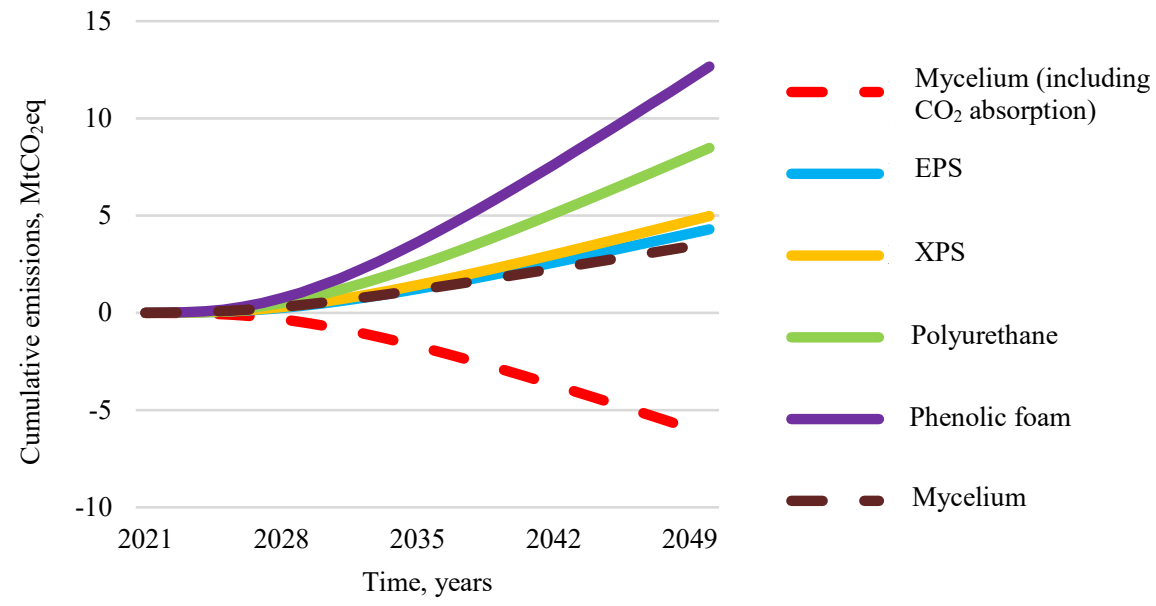

Fig. 3. Cumulative GHG emissions from insulation material production.

\subsection{Accumulated Energy Consumption}

Results of the embodied energy show that the mycelium insulation material has the highest embodied energy per cubic meter of material (Fig. 4). Therefore, the mycelium insulation cumulative energy consumption value is the highest equal to $337 \mathrm{PJ}$. The cumulative energy 
consumptions of the synthetic materials are - EPS 65.6 PJ, XPS 58.6 PJ, polyurethane 154.1 PJ, and phenolic foam 95.9 PJ.

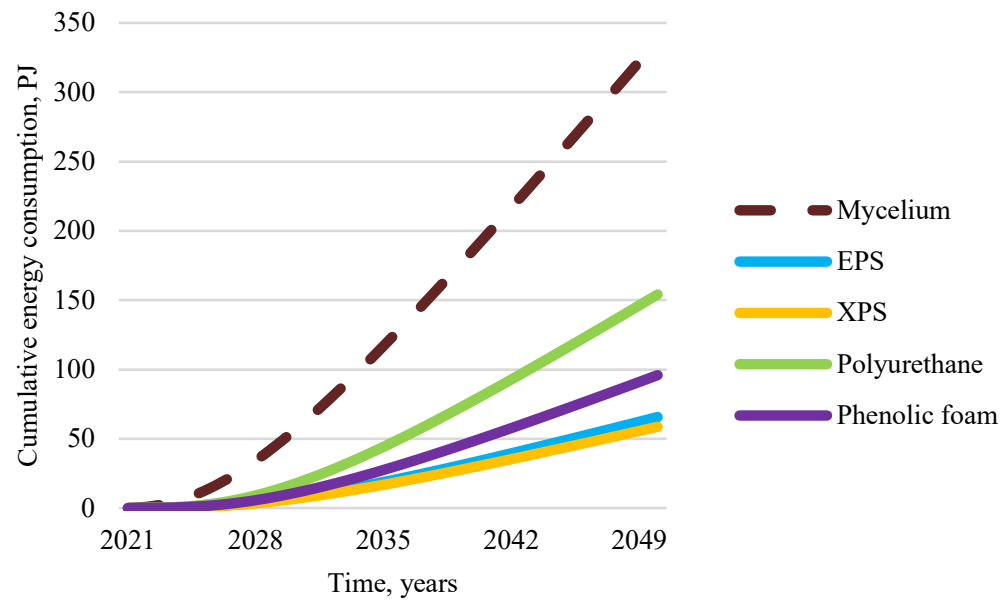

Fig. 4. Cumulative energy consumption from insulation material production.

\subsection{Feed-back Effects on Avoided Emissions}

When feed-back effects of using revenues from displaced carbon emissions for funding R\&D and land allocation for production of the renewable insulation material (see Fig. 3) are included amount of cumulative avoided emissions when use of synthetic materials is compared with use of the mycelium insulation materials reach nearly $19 \mathrm{MtCO}_{2} \mathrm{eq}$ (see Fig. 5).

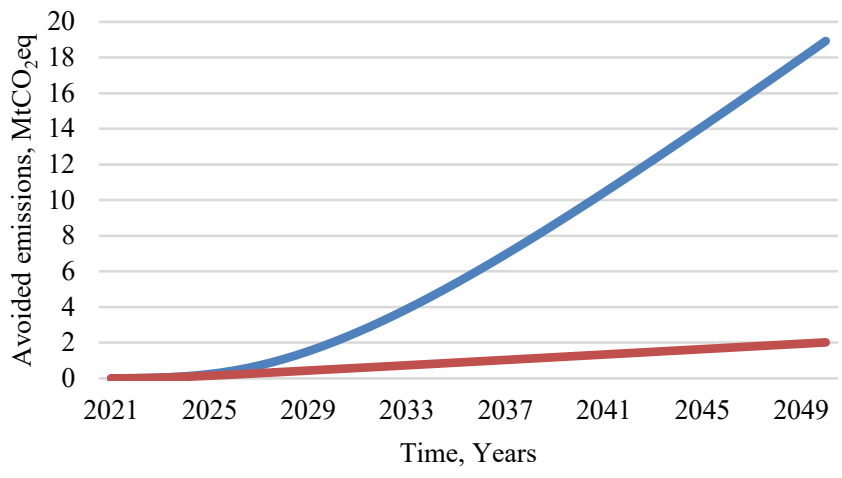

Feed-back effects are included

$\longrightarrow$ Feed-back effects are excluded

Fig. 5. Cumulative avoided GHG emissions when the emissions of the mycelium material is compared with the emissions resulting from phenolic foam, with feed-back effects included and excluded. 
If the feed-back effects are excluded the avoided cumulative emissions are only circa $2 \mathrm{MtCO}_{2}$ eq. When the feed-back effects are included, revenues from sales of carbon allowances are invested in R\&D, which increases production yield of the land used and energy efficiency of production (both of power and heat use). Revenues also allow to allocate more land for prodcution. All these effects are absent when no feed-backs are considered. Comparsion in Fig. 5 is obtained by comparing the emissions resulting from the mycelium material production with the emissions resulting from production of the phenolic foam insulation.

\section{Conclusions}

Comparing the mycelium insulation with other synthetic materials in terms of embodied GHG emissions shows that the mycelium insulation production is less emitting, mainly due to $\mathrm{CO}_{2}$ absorbtion by the materials involved in production. Therefore, switching from synthetic insulation material production to mycelium insulation production would result in lower annual GHG emissions and lower emissions accumulated in the atmosphere. The way insulation material is produced impacts embodied emissions in cradle-to-gate life cycle analysis, but the average synthetic material embodied emission value is higher than the mycelium insulation material. Therefore, more studies should be concluded regarding comparison of organic insulation materials with synthetic in terms of different types of production. When $\mathrm{CO}_{2}$ absorption is included in calculations, results show that the mycelium insulation can sequester up to $298 \mathrm{kgCO}_{2} / \mathrm{m}^{3}$, meaning that the mycelium insulation material is carbon negative. As cumulative emission results show, production of the mycelium insulation would be more favored towards reduction of GHG emissions in insulation material production. Namely, producing mycelium insulation instead of phenolic foam would result in $18.9 \mathrm{MtCO}_{2}$ eq emissions avoided in the considered time span.

Most of the embodied energy comes from material use for production. As of cumulative energy consumption results, mycelium insulation is the most energy-consuming. Mycelium insulation material is not competitive with synthetic materials in terms of energy consumption during the cradle-to-gate life cycle, therefore research towards alternative material use and energy requirement to reduce energy requirement in production should be concluded. Likewise, to study emissions more production variations should be examined.

Feed-back effects play an important role in stimulating production process. Revenue flow from avoided emissions increases production rate of renewable insulation material creating positive feed-back loop. Therefore, feed-back effects associated with avoided emissions by substituting renewable for synthetic materials in production of heat insulation materials have to be considered.

\section{ACKNOWLEDGEMENT}

This study has been funded by the Latvian Council of Science within the research project 'Simulator for transition to sustainable energy systems (SET4LOW)' No. 1zp-2020/2-0191.

\section{REFERENCES}

[1] Jones M., et al. Waste-derived low-cost mycelium composite construction materials with improved fire safety. Fire Mater. 2018:42(7):816-825. https://doi.org/10.1002/fam.2637

[2] Dougoud M. Mycelium Infrastructures for Impermanent Futures. Thesis. Washington: University of Wahington, 2018.

[3] Islam M. R., et al. Mechanical behavior of mycelium-based particulate composites. J. Mater. Sci. 2018:53:1637116382. https://doi.org/10.1007/s10853-018-2797-z 
[4] Fallis A. Development and Testing of Mycelium-Based Composite Materials for Shoe Sole Applications. J. Chem. Inf. Model. 2013:53(9):1689-1699.

[5] Mazur R. Mechanical Properties of Sheets Comprised of Mycelium: A Paper Engineering Perspective. Honor. Theses 2015:68.

[6] Butu A., et al. Mycelium-based materials for the ecodesign of bioeconomy. Dig. J. Nanomater. Biostructures 2020:15(5):1129-1140.

[7] Appels F. V. W., Wösten H. A. B. Mycelium Materials. Encyclopedia of Mycology 2021:2:710-718. https://doi.org/10.1016/b978-0-12-809633-8.21131-x

[8] Girometta C., et al. Physico-mechanical and thermodynamic properties of mycelium-based biocomposites: A review. Sustain. 2019:11(1):281. https://doi.org/10.3390/su11010281

[9] Abhijith R., Ashok A., Rejeesh C. R. Sustainable packaging applications from mycelium to substitute polystyrene: A review. Mater. Today Proc. 2018:5(1):2139-2145. https://doi.org/10.1016/j.matpr.2017.09.211

[10] Elsacker E., et al. A comprehensive framework for the production of mycelium-based lignocellulosic composites. Sci. Total Environ. 2020:725:138431. https://doi.org/10.1016/j.scitotenv.2020.138431

[11] Lelivelt R. J. J. The mechanical possibilities of mycelium materials. Master Thesis. Eindhoven: Eindhoven University of Technology, 2015.

[12] Haneef M., et al. Advanced Materials from Fungal Mycelium: Fabrication and Tuning of Physical Properties. Sci. Rep. 2017:7:1-11. https://doi.org/10.1038/srep41292

[13] Javadian A., et al. Application of Mycelium-Bound Composite Materials in Construction Industry: A Short Review. 2020.

[14] Ojanen T., Seppä I. P., Nykänen E. Thermal insulation products and applications - Future road maps. Energy Procedia 2015:78:309-314. https://doi.org/10.1016/j.egypro.2015.11.649

[15] Tsao Y. Characterization of mycelium- based composites as foam-like wall insulation material. Master Thesis. Eindhoven: Eindhoven University of Technology, 2020.

[16] Honors E., et al. Investigations of Mycelium as a Low-carbon Building Material Investigations of Mycelium as a Lowcarbon Building Material. Hanover: Thayer School of Engineering, 2020.

[17] Forrester J. W. Counterintuitive behavior of social systems. Technol. Forecast. Soc. Change 1971:3:1-22. https://doi.org/10.1016/S0040-1625(71)80001-X

[18] Binder T., et al. Developing system dynamics models from causal loop diagrams. Proc. 22nd Int. Conf. Syst. Dyn. Soc. 2004:1-21.

[19] Zadražil F. Influence of $\mathrm{CO}_{2}$ concentration on the mycelium growth of three pleurotus species. Eur. J. Appl. Microbiol. 1975:1(4):327-335. https://doi.org/10.1007/BF01382692

[20] City of Winnipeg. Emission factors in $\mathrm{kg} \mathrm{CO}_{2}$-equivalent per unit. WSTP South End Plant Process Selection Report. Winnepeg: CW, 2011.

[21] Tanaka H. Thermal distillation system utilizing biomass energy burned in stove by means of heat pipe. Alexandria Eng. J. 2016:55(3):2203-2208. https://doi.org/10.1016/j.aej.2016.06.008

[22] Rein P. W. The carbon footprint of sugar. Zuckerindustrie 2010:135(7):427-424. https://doi.org/10.36961/si10006

[23] Saunders C., et al. Food Miles - Comparative Energy/Emissions Performance of New Zealand's Agriculture Industry. Research report No. 285. Lincoln: Lincoln University New Zealand, 2006.

[24] Yusuf M. A., et al. Potential of Traditional Sago Starch: Life Cycle Assessment (LCA) Perspective. IOP Conf. Ser. Mater. Sci. Eng. 2019:507(1):012014. https://doi.org/10.1088/1757-899X/507/1/012014

[25] Godart C., et al. LCA of Starch Potato From Field To Starch Production Plant Gate. Presented at the 8th Int. Conf. LCA Agri-Food Sect., 2012.

[26] Flysjö A. Greenhouse gas emissions in milk and dairy product chains. Improving the carbon footprint of dairy products Greenhouse gas emissions in milk and dairy product chains improving the carbon footprint of dairy products. PhD Thesis. Aarhus: Aarhus University, 2012.

[27] Wood S., Cowie A. For Fertiliser Production . Cooperative Research Centre for Greenhouse Accounting. New South Wales: Research and Development Division, 2004

[28] Vittuari M., De Menna F., Pagani M. The hidden burden of food waste: The double energy waste in Italy. Energies 2016:9(8):660 https://doi.org/10.3390/en9080660

[29] Chang I., Im J., Cho G. C. Introduction of microbial biopolymers in soil treatment for future environmentally-friendly and sustainable geotechnical engineering. Sustainability 2016:8(3):251. https://doi.org/10.3390/su8030251

[30] FAO/WHO. Combined Compendium of Food Additive Specifications. All specifications monographs from the 1st to the 65th meeting (1956-2005). FAO JECFA Monogr. Rome: FAO, 2006.

[31] Dove C. A., Bradley F. F., Patwardhan S. V. A material characterization and embodied energy study of novel clayalginate composite aerogels. Energy Build. 2019:184:88-98. https://doi.org/10.1016/j.enbuild.2018.10.045

[32] Santana M. V. E., Zhang Q., Mihelcic J. R. Influence of Water Quality on the Embodied Energy of Drinking Water Treatment. Environ. Sco. Technol. 2014:48(5):3084-3091. https://doi.org/10.1021/es404300y

[33] Sgarbossa A., et al. Comparative life cycle assessment of bioenergy production from differentwood pellet supply chains. Forests 2020:11(11):1-16. https://doi.org/10.3390/f11111127 
[34] May B., et al. Cradle-to-gate inventory of wood production from Australian softwood plantations and native hardwood forests: Embodied energy, water use and other inputs. For. Ecol. Manage. 2012:264:37-50. https://doi.org/10.1016/j.foreco.2011.09.016

[35] Wiśniewski P., Kistowski M. Greenhouse gas emissions from cultivation of plants used for biofuel production in Poland. Atmosphere 2020:11(4):1-12. https://doi.org/10.3390/ATMOS11040394

[36] Straw-Bale [Online]. [Accessed 07.05.2021]. Available: https://materialspalette.org/straw-bale

[37] Havrysh V., et al. Life Cycle Energy Consumption and Carbon Dioxide Emissions of Agricultural Residue Feedstock for Bioenergy. Appl. Sci. 2021:11(5):2009. https://doi.org/10.3390/app11052009

[38] VARAM. Siltumnīcefekta gāzu emisiju aprēkina metodika (Greenhouse gas emission calculation methodology) [Online]. [Accessed 30.04.2021]. Available: https://www.varam.gov.lv/lv/siltumnicefekta-gazu-emisiju-aprekinametodika

[39] Blumberga A., et al. System dynamics model of a biotechonomy. J. Clean. Prod. 2018:172:4018-4032. https://doi.org/10.1016/j.jclepro.2017.03.132 